\title{
AS BASES SOCIAIS E ATITUDINAIS DA ALIENAÇÃO ELEITORAL NO BRASIL
}

Julian Borba

\begin{abstract}
Resumo
Um dos pressupostos centrais da teoria da cultura política é que os sentimentos, crenças e valores políticos da cidadania se materializam em padrões comportamentais. Partindo desses pressupostos mais gerais da teoria da cultura política, esse artigo pretende analisar se o comportamento eleitoral alienado (abstenção, voto branco e voto nulo) pode ser compreendido a partir do uso de indicadores de cultura política. Os poucos trabalhos sobre o tema no Brasil, trataram das bases sócio-econômicas e demográficas da alienação e utilizaram como referência os dados oficiais de comparecimento eleitoral. De modo diferente à referida literatura, nossa base empírica foi um survey pós-eleitoral (ESEB), o qual permitiu testar e comparar a hipótese culturalista com outras explicações para a alienação eleitoral.
\end{abstract}

Palavras-chave: Participação Política; Cultura Política; Alienação Eleitoral.

\begin{abstract}
One of the central premises of the theory of political culture is that feelings, beliefs and political values regarding citizenship become materialized into behavioral patterns. Starting from these more general pressupositions of political theory, the article intends to analyze whether the alienated electoral behavior (abstention or blank vote) may be understood through the use of political culture indicators. The few works dealing with the issue in Brazil draw on the socio-economic and demographic bases of alienation as well as official election turnout data for reference. Our empirical basis, by contrast, is a postelection survey (by ESEB) which allows us to test and compare the culturalist hypothesis with other explanations for electoral alienation.
\end{abstract}

Key-words: Political Participation; Political Culture; Electoral Alienation.

\section{Introdução}

O decréscimo nos índices de participação eleitoral tem se tornado um fenômeno global no mundo das democracias representativas ${ }^{1}$. Os significados de tal fenômeno têm sido objeto de profundas discordâncias entre os cientistas políticos. De um lado, estão aqueles que advogam que determinados índices de não participação eleitoral são não apenas aceitáveis, mas até mesmo desejáveis para a estabilidade democrática (ALMOND e VERBA, 1963; LIPSET, 1967). De outro, estão situados aqueles que interpretam o fenômeno como um sinal preocupante, podendo significar desde um déficit de legitimação do regime até sinais

1 Um panorama, tanto da literatura internacional, quanto dos dados sobre participação eleitoral encontra-se em Costa (2007). 
de desagregação social (LANCELOT apud VITULLO, 2007).

A não participação eleitoral (abstenção), somada àqueles eleitores que comparecem às urnas, mas optam por anular ou votar em branco, caracteriza o que tem sido denominado de alienação eleitoral. O presente artigo tem como objetivo analisar suas bases sociais e atitudinais, no Brasil.

Mais do que fazer um diagnóstico da democracia brasileira a partir de alguns dados empíricos sobre alienação, o que pretendemos aqui é dialogar com os pressupostos de duas das grandes correntes da análise política contemporânea, quais sejam, as teorias da escolha racional e as teorias da cultura política. De maneira geral, pode-se dizer que são essas duas perspectivas que têm orientado boa parte do debate internacional e nacional sobre o tema.

O artigo está organizado em três partes: na primeira, fazemos uma breve apresentação do debate analítico envolvendo as teorias da cultura política e da escolha racional, em especial como tais abordagens tratam o tema da participação/alienação eleitoral. Na segunda parte, fazemos uma breve apresentação das interpretações sobre a alienação eleitoral no Brasil. Por fim, na terceira parte, são apresentados e analisados os nossos dados empíricos.

\section{Cultura política e escolha racional na análise política contemporânea}

Algumas das principais divergências na teoria social contemporânea são relacionadas ao ponto de partida analítico. O que deve ter precedência, o indivíduo ou a sociedade? $O$ ator ou a estrutura? No campo da teoria política, tais questões podem ser relacionadas à disputa entre os paradigmas da economia e da sociologia² (Cf. REIS, 2000) e sua pertinência na explicação dos fenômenos da vida política (BARRY, 1970).

Iniciamos com a teoria da escolha racional (TER). Nas palavras

\footnotetext{
${ }^{2}$ Quando utilizamos a expressão sociologia tradicional não estamos nos referindo a uma tradição específica do pensamento sociológico, e sim ao pressuposto básico de todo o pensamento sociológico, desde Durkheim, de que a sociedade exerce uma coerção sobre o indivíduo.
} 
de Przeworski (1988, p. 5), a teoria da escolha racional é uma proposta epistemológica que se propõe a

fornecer microfundamentos para os fenômenos sociais e, especificamente, basear toda a teoria da sociedade nas ações dos indivíduos concebidas como orientadas para a realização de objetivos racionais.

Tomando essas considerações, a teoria da escolha racional propõe-se à fundação de um conhecimento generalizante da vida política e social. A idéia é simples: tomando o indivíduo portador de racionalidade estratégica como fundamento, é possível deduzir as preferências dos atores sociais. Em qualquer estudo inspirado pela teoria da escolha racional, as preferências não são tematizadas; elas estão dadas. Diante desse fato, transfere-se o foco de preocupação nesses estudos para as instituições (sociais e políticas), que são analisadas quanto ao seu papel e/ou capacidade em resolver problemas de coordenação da ação. É nesse sentido que derivam afirmações tão difundidas na discussão contemporânea da ciência política sobre o papel das escolhas institucionais na produção de resultados políticos (estabilidade de regimes, políticas públicas, etc.).

A aplicação dos pressupostos da teoria da escolha racional à decisão eleitoral encontra aplicação pioneira na obra de Anthony Downs (1998). Segundo o autor, a decisão entre o comparecimento e a abstenção é mediada por um cálculo feito pelo eleitor. No caso, se os benefícios esperados pelo voto forem maiores que seus custos, ele vota, caso contrário, se abstém.

$\mathrm{Na}$ contraposição a tal perspectiva, apresentam-se várias abordagens que, genericamente poderíamos chamar de análises societárias da política. Nessas perspectivas, os processos políticos são explicados menos pelos seus elementos intrínsecos (regras do sistema, história, dinâmica de competição), do que extrínsecos.

Entre tais abordagens iremos nos deter na teoria da cultura política, na forma como foi operacionalizada pela tradição iniciada por 
Almond e Verba $(1963)^{3}$, e que tem seus desdobramentos posteriores na obra de autores como Inglehart (1998; 2002), Putnam (1996; 2000), Eckstein (1988) e Pipa Norris (2002) ${ }^{4}$. Tal opção justifica-se pelo fato de ser essa a tradição intelectual que mais fortemente vem questionando os pressupostos e concepções da escolha racional.

$\mathrm{Na}$ forma como foi pensado pelos fundadores da disciplina, o conceito de cultura política estava delimitado às atitudes e orientações dos cidadãos em relação aos assuntos políticos: "O termo cultura política refere-se às orientações especificamente políticas, às atitudes com respeito ao sistema político, suas diversas partes e o papel dos cidadãos na vida pública" (ALMOND e VERBA, 1989, p. 12, grifos nossos). Através de tal conceito, visava-se a chegar à caracterização daquilo que seria a cultura política de uma nação, definida como "[...] a distribuição particular de padrões de orientação política com respeito a objetos políticos entre os membros da nação" (ibidem, p. 13) ${ }^{5}$.

Para além do conceito de cultura política, nos interessa aqui apontar para o pressuposto que guia tais estudos, qual seja, o de que o comportamento político é produto dos valores e crenças compartilhadas pelos indivíduos. Em outras palavras, enquanto para as TER existe um pressuposto comportamental que não é tematizado (ação estratégica),

\footnotetext{
${ }^{3}$ Isto não significa que a preocupação com a cultura política não estivesse presente nos estudos políticos anteriores a Almond e Verba. Como destaca Baquero (2002, p.111) "embora já estivessem presentes, no horizonte da política clássica desde os estudos de Platão, Aristóteles e Sócrates a preocupação com a capacidade política dos cidadãos e o seu papel na sociedade, os debates que surgem na década mencionada (anos 60) começam a ser pautados por uma nova perspectiva de análise, e possibilita o surgimento de uma nova área de estudo, qual seja, a da política comparada empírica". Castro (2000) também destaca que o que diferencia "os estudos dos últimos 30 ou 40 anos dos anteriores, [...] não é o tema, mas a abordagem teórica, e acima de tudo, o instrumental metodológico" (CASTRO, 2000, p.20). Para uma genealogia do conceito de cultura política, vide Almond (1989).

${ }^{4}$ Tal abordagem é tributária da teoria do desenvolvimento político. Sua associação com tal teoria está em comungar com o pressuposto de que os processos de modernização, cujos indicadores centrais são os fenômenos da industrialização e urbanização, provocariam mudanças significativas nos padrões de comportamento político e eleitoral, os quais levariam a mudanças no plano institucional.

${ }^{5} \mathrm{Na}$ forma como foi pensado pelos fundadores da disciplina, o conceito de cultura política assumia um forte viés normativo. A preocupação de Almond e Verba era, sobretudo, com a estabilidade democrática e as condições culturais para o estabelecimento da democracia "[...] entendida como o sistema político norte-americano, em contraposição ao socialismo soviético" (CASTRO, 2000, p.17). Deste modo, as análises visavam a responder a uma dupla demanda: "por um lado, reforçar e justificar a compreensão da supremacia da sociedade norte-americana como modelo a ser seguido; por outro, promover e justificar a política norte-americana $[\ldots]^{\prime \prime}$ (ibidem).
} 
para os culturalistas, entender a forma como os indivíduos estruturam suas crenças (CONVERSE, 1964) e como estas se materializam em diferentes tipos de comportamento, é o problema fundante da análise política (ALMOND, 1999).

Nesse sentido, para essa perspectiva, analisar o comportamento alienado significa pensar nos valores e crenças políticas que estruturam a decisão do indivíduo em não participar (abstenção) ou rejeitar as ofertas que são colocadas a ele pelo mercado eleitoral (voto nulo ou branco). O que alguns estudos apontam é que tal comportamento é fruto de uma situação de descrença e desencanto para com a política e com a democracia existente (VITULLO, 2007; BAQUERO e PRÁ, 2007).

$\mathrm{Na}$ próxima seção, veremos como as duas perspectivas aqui apresentadas se materializam em visões também diferenciadas sobre os significados da alienação eleitoral no Brasil.

\section{A literatura sobre alienação eleitoral}

O fenômeno da alienação eleitoral no Brasil, apesar de amplamente estudado, historicamente foi tratado de forma secundária pela literatura, aparecendo "[...] como parte de trabalhos mais gerais sobre o sistema eleitoral e partidário" (COSTA, 2007, p. 256).

Sem a pretensão de uma revisão sistemática sobre o fenômeno da alienação, apresentaremos aqui, algumas linhas gerais em que se desenvolveu o debate no Brasil $^{6}$. Como já destacado em outros trabalhos, a alienação eleitoral no país foi abordada como tendo múltiplas causas, sendo que as principais abordagens recorreram a algumas proposições explicativas sobre o tema.

Considerando essa dimensão analítica, o que queremos destacar é que os modelos explicativos, de maneira geral, podem ser classificados segundo o pressuposto comportamental (se tematizado ou não) adotado pelos estudos. Nesse sentido, podemos fazer a seguinte classificação das pesquisas:

a) trabalhos que adotam um conceito forte de racionalidade do eleitor. Aqui, podemos incluir as pesquisas como as de Santos (1987),

${ }^{6}$ Sobre o tema, indicamos mais uma vez, o excelente trabalho de Costa (2007).

REVISTA DEBATES, Porto Alegre, v. 2, n. 2, p. 134-157, jul.-dez. 2008. 138 
Lima Júnior (1993), e Nicolau (2002). Para além de eventuais discordâncias sobre o tema, tais autores compartilham com determinados pressupostos de racionalidade que são definidores da ação, os quais são originários da perspectiva da racional choice. Vejamos algumas interpretações.

Wanderley Guilherme dos Santos, em Crise e Castigo (1987) ao estudar as taxas de alienação eleitoral no período compreendido entre 1945 e 1982, assim se posiciona quanto ao fenômeno:

[...] quanto maior a credibilidade do processo político formal, maior será a taxa de alienação eleitoral. Credibilidade entra aqui como um conceito que busca captar a importante dimensão retorno esperado do voto, utilizada por Huntington-Nelson, cumulativamente associada à dimensão institucionalização do respeito aos resultados eleitorais. Apesar da longa nomenclatura, esta é uma dimensão extremamente relevante na decisão de participar eleitoralmente ou não. Quanto maior for a incerteza de que o desdobramento do processo político se fará de acordo com os resultados eleitorais, tanto maior o peso da dimensão retorno esperado do voto, e tanto maior o incentivo à alienação (SANTOS, 1987, p. 45, grifos do autor).

Veja-se que o ponto de partida analítico é um cálculo que o eleitor faz entre os custos da participação e os resultados esperados. Se, nesse caso, os ganhos (resultado esperado do voto), forem maiores que os custos (e a incerteza), ele vota, caso contrário, se comporta de forma alienada.

Olavo Brasil de Lima Júnior adota perspectiva semelhante à de Santos, porém faz uma distinção quanto ao significado das abstenções e dos votos brancos e nulos. Para o autor, o argumento de Santos é "bastante persuasivo", porém "pode-se objetar", que "o que leva o eleitor a abster-se não é exatamente o que leva o eleitor a votar em branco" (LIMA JÚNIOR, 1993, p. 101). Mesmo compartilhando com Santos sobre a lógica do cálculo custo-benefício, propõe que o mesmo seja desmembrado em dois momentos distintos:

[...] esse cálculo é analiticamente antecipado pelo 
eleitor, isto é, a decisão final a ser tomada por ele implica escolher o candidato, porém, antes, cabe-lhe decidir se vai ou se pode comparecer às urnas. De certa forma, a primeira decisão está condicionada pela segunda, dentro da lógica do cálculo racional. E é verdade; porém há fatores que estreitam o campo decisório do eleitor, facilitando ou criando obstáculos para o livre e efetivo exercício do direito (obrigação) de votar. Refiro-me às condições de acesso às cabines eleitorais (idem).

O argumento de Lima Júnior, dessa forma, vai no sentido de que os determinantes do absenteísmo seriam de "natureza ecológica", os quais "facilitam, dificultam ou impedem o deslocamento do eleitor até as urnas" (idem, p. 103). Já os votos brancos e nulos estariam associados a "atributos sócio-econômicos de natureza individual" (idem).

Jairo Nicolau (2002) é outro autor que incluímos entre os racionalistas fortes, não porque tenha uma formulação sistemática sobre o assunto, mas porque, em nossa opinião, implicitamente, compartilha com os pressupostos comportamentais da TER. A sua diferença com os autores acima citados é que dá um grande destaque para a mediação das instituições na definição do cálculo estratégico realizado pelo eleitor. O autor também critica Santos por considerar o fenômeno da abstenção e dos votos brancos e nulos, como expressão de um mesmo fenômeno (a alienação). Com relação às taxas de comparecimento eleitoral, ao comparar o Brasil com outros países, afirma que "não há nada de errado com a taxa de comparecimento do Brasil" (NICOLAU, 2002, p. 282 ). Já com relação aos votos brancos e nulos, sua interpretação é a de que questões sócio-econômicas e institucionais jogariam um peso explicativo central. Para o autor

[...] tal fenômeno não é, exclusivamente resultado do protesto contra o sistema político (ou contra o voto, obrigatório), mas resultado de uma combinação perversa entre cidadãos de baixíssima escolaridade e uma cédula eleitoral que estava entre as mais complexas do mundo. A urna eletrônica, criada para dar cabo das fraudes, produziu a mais profunda reforma política dos anos recentes: ao facilitar o voto, permitiu que milhões de votos anulados por erro passassem a ser contabilizados para os partidos e candidatos, e ainda estimulou um contingente de 
eleitores que deixavam a cédula em branco ao votar (NICOLAU, 2002, p. 294).

b) Um segundo grupo de autores que aborda o tema da alienação eleitoral, é aquele que denominamos de racionalistas contextuais. Em outras palavras, se mantém a idéia de um conceito monológico de racionalidade, a qual, porém, se manifesta em diferentes níveis ou contextos $^{7}$. O conceito de racionalidade aqui é associado a um plano cognitivo e se relaciona profundamente aos níveis sócio-econômicos dos eleitores $^{8}$. Se tal plano de análise já está presente nos trabalhos de Lima Júnior (1993) e Nicolau (2002), comentados anteriormente, é nas pesquisas de Fábio Wanderley Reis $(1978,2000)$ e Mônica Castro $(1994)^{9}$ - através do uso do conceito de sofisticação política - que vai ter desdobramentos analíticos mais profícuos. A aplicação de tal referencial ao estudo da alienação eleitoral foi desenvolvida por Tostes (apud COSTA, 2007). Tal pesquisa, segundo Costa (2007, p. 160) foi a "primeira" e "mais sistemática" sobre alienação eleitoral no país. A perspectiva do autor é que

\footnotetext{
${ }^{7}$ Em artigo de 2002, Reis assim se posiciona sobre essas questões: "A dificuldade pode ser traduzida em termos de que não há como recorrer de maneira consistente e conseqüente ao postulado de racionalidade, nem aplicá-lo na explicação do que quer que seja, sem que haja informação adequada a respeito do contexto no qual os indivíduos atuam. Se nada se sabe sobre o contexto, como afirmar se o indivíduo está sendo racional ou não, ou apreciar eventualmente o grau de racionalidade de sua ação? Para que se possa resgatar o cálculo do agente, e assim avaliar sua racionalidade, é preciso ter informação a respeito daquilo que a literatura da escolha racional costuma descrever como a estrutura de oportunidades. Ora, isso supõe informação sobre o contexto da ação" (REIS, 2002, p. 48).

${ }^{8}$ A idéia de racionalidade e seus níveis, para Reis, está associada à compreensão. Nas palavras do Reis: "Nesse sentido, bem claramente, a apreensão da racionalidade supõe a compreensão: supõe que eu possa me colocar nos chinelos do outro, ver o mundo com os olhos do outro. Por outro lado, o sentido preciso que se pode atribuir à idéia de compreensão é exatamente o sentido em que se trata de resgatar o cálculo realizado pela pessoa a ser compreendida. Compreendemos um texto remoto quando conseguimos visualizar os objetivos quando que o autor tinha em mente quando o escreveu - e assim resgatar, de alguma forma, o cálculo feito por ele. Portanto, ao invés do contraste que à primeira vista haveria entre as perspectivas que costumam dar ênfase à racionalidade, por um lado, e à compreensão, por outro, temos antes uma afinidade fundamental entre as duas, e seria preciso evitar os equívocos sempre renovados que resultam da contraposição ingênua entre elas [...]" (REIS, 2002, p. 48).

9 O conceito de sofisticação política foi originalmente formulado por Neuman (1986), possuindo as seguintes dimensões: saliência, conhecimento da política e capacidade de conceituação política. Mônica Castro (1994), em sua tese de doutorado, operacionaliza tal conceito a partir do somatório de quatro variáveis: o interesse por política, o envolvimento no processo eleitoral, a exposição ao programa eleitoral gratuito na televisão e o grau de informação a respeito dos candidatos a presidente da república.
} 
atributos sociais, cognitivos e políticos dos eleitores são uma das dimensões importantes quando se tenta explicar causalmente o comportamento político e, particularmente, o eleitoral. Percepção, atitudes e comportamento dos indivíduos passam, necessariamente, pela sua forma de inserção no mundo social, pelas relações e identidades que aí estabelecem (TOSTES apud COSTA, 2007, p. 160).

c) Um terceiro grupo de autores entende a alienação eleitoral como um fenômeno societário, o qual possui inúmeros significados, dependendo do contexto e dos atores que expressam esse tipo de comportamento. O mais comum, nessa linha de interpretação, é que a alienação seja percebida como uma forma de protesto político, manifestando o descontentamento dos indivíduos para com as instituições e/ou processos políticos vigentes. A associação da alienação ao protesto político foi realizada por autores como Soares (1973), Lamounier (1978), Reis (1978), Trindade e Cew (1978) e Stamatto (1984), ao analisar o comportamento de determinadas parcelas da população no período do regime militar. Trabalhos mais recentes, como os de Vitullo (2002, 2007), interpretam o crescimento do comportamento alienado aos processos de desestruturação social e crise de legitimidade, do modelo de democracia dominante na América Latina. Nas palavras de Vitullo (2002, p. 224), o fenômeno da alienação, aliado a volatilidade eleitoral e personalização da política, seriam "sintomas evidentes da severa desestruturação social e conseqüente apatia e desinteresse pela política que sofrem as grandes massas no Brasil e Argentina" (idem, tradução nossa). Da mesma forma, Baquero (1999, p. 28, grifos do autor) comentando sobre a apatia política nos países da América Latina, propõe uma interpretação sobre suas causas:

A apatia nesses países é muito mais conseqüência da
estruturação de uma cultura política marcada pela
influência de duas éticas, a religiosa e a política. A
primeira gera atitudes disciplinadas e constituídas no
campo da moral, enquanto a segunda é propícia para
aceitação do vale tudo, inclusive entre aqueles que têm
altos graus de sofisticação política. Nesse sentido, as
atitudes de desconfiança e desencanto com as
instituições políticas, particularmente com os partidos 
políticos, se dão no sentido da desvalorização concreta dessas instituições políticas, gerando uma cultura política altamente personalista no sentido estrutural. Assim configurada, a cultura política é altamente deletéria no estabelecimento de parâmetros que contribuam para a solidez democrática.

Em trabalho mais recente, Baquero e Prá (2007) avaliam a não participação no Brasil como estando relacionada aos fenômenos da apatia, do cinismo, da alienação e da anomia (2007, p.156). Cada um desses conceitos tem significados próprios na argumentação dos autores, estando, porém associados a um significado mais geral de desintegração e ausência de legitimidade das instituições políticas existentes.

\section{A alienação eleitoral no Brasil: buscando compreender seus significados}

Na tentativa de caracterizar o problema que estamos abordando nesse trabalho, apresentamos abaixo alguns dados relativos à evolução da alienação eleitoral no Brasil (eleições presidenciais de 1989 a 1996).

Gráfico 1 - Abstenções, brancos e nulos Presidente da República 1989-2006 (\%)

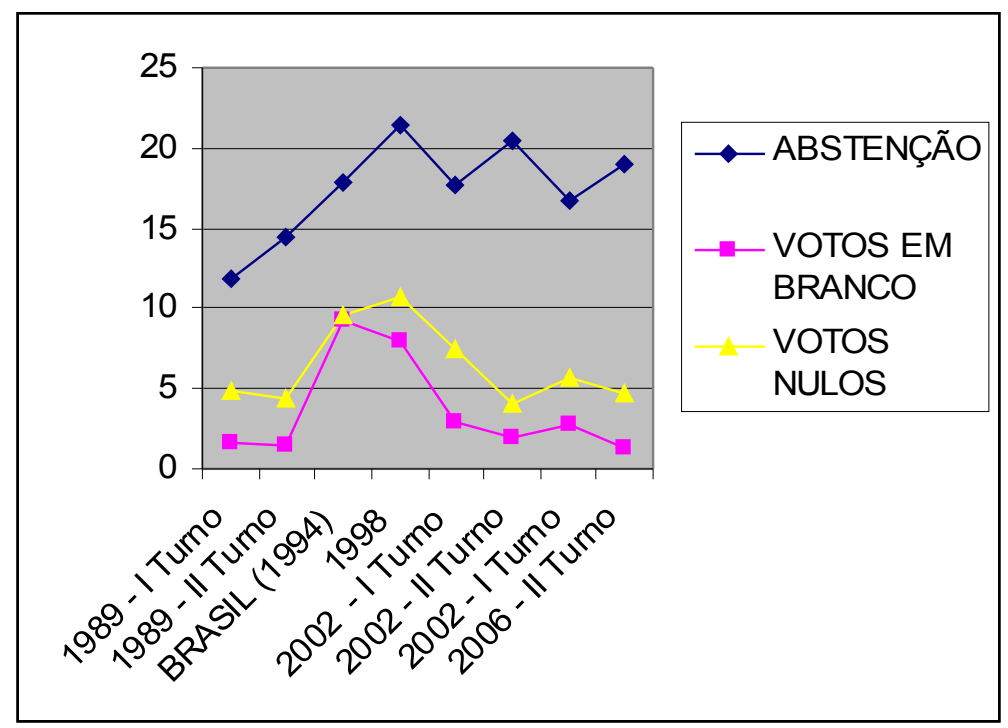

Fonte: NICOLAU, Jairo. Dados eleitorais do Brasil. Disponível em $<$ http://jaironicolau.iuperj.br>. Acesso em: 01 jul. 2008. 
Conforme pode ser identificado no gráfico, o que se verifica é um aumento significativo das abstenções quando se compara 1989 a 2006. Nesse intermédio, houve variações ascendentes e descendentes, com as últimas eleições presidenciais registrando, em seu primeiro turno, um aumento de $4,8 \%$ em relação a 1989 . Quando se compara os dois segundo turnos, a diferença cai para 4,6\%. Em relação aos valores brutos, tem-se uma média de $17,43 \%$ do eleitorado que não compareceu nos últimos oito pleitos eleitorais ${ }^{10}$. Já em relação aos votos brancos e nulos, o dado mais significativo é a sua queda a partir de 1998, fenômeno que na interpretação de Nicolau (2002) está diretamente relacionado à introdução e generalização da urna eletrônica a partir desse pleito.

A importância do fenômeno para a compreensão do processo eleitoral brasileiro, salta aos olhos, quando verificamos que nas eleições de 1989, 1994 e 2002, o comportamento alienado foi numericamente superior aos votos obtidos pelo segundo colocado na disputa presidencial; e em 1998 foi maior mesmo que a votação do presidente reeleito, e somente a abstenção já foi maior que os votos do segundo colocado (Cf. COSTA, 2007, p.255).

Gráfico 2 - Votos Brancos e Nulos - Câmara dos Deputados, Governadores e Presidente da República - 2002 e 2006 (I Turno). 2002 - 2006

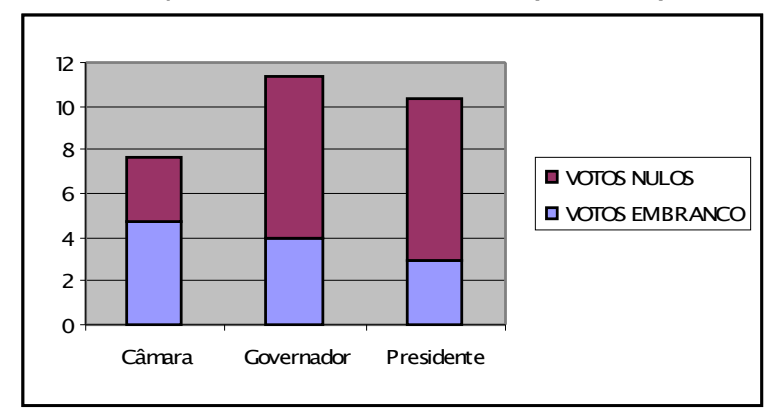

\footnotetext{
${ }^{10} \mathrm{Em}$ anexo, apresentamos tabelas com os percentuais de abstenções, brancos e nulos nas eleições para a Câmara dos Deputados, Governadores e Presidente da República e Prefeito.
} 


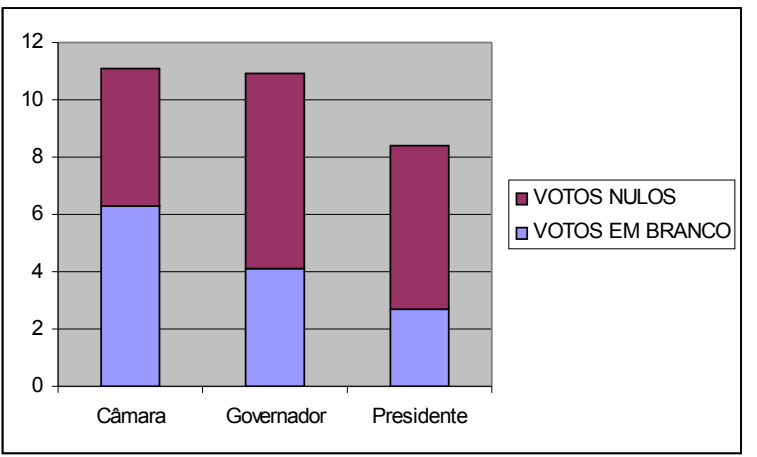

Fonte: Nicolau, Jairo. Dados eleitorais do Brasil. Disponível em <http://jaironicolau.iuperj.br>. Acesso em: 01 jul. 2008.

Os gráficos acima são uma tentativa de verificar a existência de diferenças entre votos brancos e nulos, quando se compara o tipo de cargo em disputa. Os dados apontam para variações entre eleições, porém são relativamente estáveis na sua distribuição entre os cargos. Nas eleições de 2002 foram os governadores os donos de maiores percentuais de brancos e nulos. Já em 2006 são os deputados, os quais tiveram o menor percentual em 2002. Explicações para essas variações podem ser buscadas desde o contexto das eleições até nas características institucionais de nosso sistema político. Deve-se ressaltar, porém que a análise agregada dos dados pode ser fonte de muitas distorções de interpretação, escondendo variações significativas em termos das bases geográficas, sociais e políticas da alienação eleitoral.

Nessa tentativa de interpretar as bases sociais da alienação, foram despendidos alguns esforços significativos de pesquisas no Brasil (SANTOS, 1987; REIS, 1991; LIMA JÚNIOR, 1993; COSTA, 2007). O último autor citado desenvolveu uma extensa pesquisa destinada a analisar os determinantes da alienação nas eleições presidenciais, de 1989 a 2002. Utilizando da análise de regressão linear pelo método dos mínimos quadrados, Costa (2007) construiu um modelo utilizando as seguintes variáveis independentes: Índice de Desenvolvimento Humano $(\mathrm{IDH})^{11}$ da região e do estado, o Índice de Exclusão Social (IES) ${ }^{12}$, a

${ }^{11}$ Desenvolvido pelo PNUD/ONU, O IDH é formado por indicadores de educação, saúde e renda.

${ }^{12}$ Desenvolvido por Pochmann e Amorim (apud COSTA, 2007). 
extensão territorial e a densidade eleitoral ${ }^{13}$. As variáveis dependentes foram os votos brancos, nulos e abstenções, sendo a última analisada de forma separada. Suas conclusões, para os pleitos analisados são de que "as condições sócio-econômicas [...] explicam, em grande parte, os votos brancos e nulos ${ }^{14}$, enquanto a abstenção é explicada, também em grande parte, pela extensão territorial [...]" (idem, p. 257).

O autor faz questão de esclarecer que essas não são as únicas variáveis explicativas do fenômeno, pois fatores institucionais, conjunturais, a mídia, etc. também influenciam nas taxas de alienação. Por fim, destaca a importância de se inserir variáveis de cultura política na análise: "outros fatores [...] não podem ser desconsiderados [...], devendo ser inseridos no quadro mais geral da descrença nos partidos e nos políticos [...] e da representação política" (idem, p.260).

Apesar de reconhecer a importância dessas variáveis, fugia do escopo do trabalho de Costa analisar o peso delas na compreensão do fenômeno da alienação. Isto é o que buscaremos desenvolver nas linhas a seguir, tomando como parâmetro empírico um survey pós-eleitoral, o ESEB 2002 (Estudo Eleitoral Brasileiro). Para fins de análise, utilizaremos apenas os dados relativos às eleições presidenciais.

Em termos metodológicos, adotamos os seguintes procedimentos: num primeiro momento, fizemos uma classificação do comportamento alienado, considerando suas expressões nos votos brancos, votos nulos e abstenções. Seguindo a orientação da literatura, organizamos os dados de forma a separar as abstenções, dos votos brancos e nulos. Tais dados foram organizados com base nas respostas às perguntas, (1) se o eleitor votou nas eleições de 2002, e (2) seu voto para Presidente no I turno em 2002.

Com relação às variáveis independentes, essas foram dividas em dois blocos: um primeiro relativo às sócio-econômicas e um segundo com as variáveis atitudinais. Para o primeiro bloco, utilizamos dados

\footnotetext{
${ }^{13}$ Extensão territorial "[...] é a área total do estado $\left(\mathrm{km}^{2}\right)$. Já a densidade eleitoral é a relação entre o total de eleitores inscritos, dividido pela extensão territorial" (COSTA, 2007, p.181). Autores como Lima Júnior (1993) e Reis (1991) testaram e comprovaram a importância dessas variáveis na explicação, principalmente da abstenção eleitoral.

${ }^{14}$ Quanto menores os IDHs e IES, maiores foram as taxas de votos brancos e nulos.
} 
relacionados à idade, sexo, escolaridade, população econômica ativa e renda familiar. Para o segundo bloco, construímos cinco índices: o índice de satisfação com as instituições políticas ${ }^{15}$, o índice de eficácia política ${ }^{16}$, o índice de satisfação com a democracia ${ }^{17}$, o índice de informação ${ }^{18}$ e o índice de clientelismo ${ }^{19}$. Para analisar os dados sócioeconômicos, fizemos o cruzamento com cada uma das variáveis dependentes e os respectivos testes de associação. O mesmo foi feito com os índices, para os quais também aplicamos a análise de variância (ANOVA), tendo em vista verificar a consistência e significância dos dados.

Uma ressalva que deve ser feita com relação à análise dos dados é que a expressão dos votos brancos, nulos e abstenção na pesquisa ESEB, foi significativamente menor que aquele verificado nos resultados eleitorais. Conforme pode ser verificado no anexo (Tabela 5), o ESEB identificou taxas de nulos e brancos nas eleições presidenciais de $1,7 \%$ e $1,0 \%$, respectivamente, enquanto que nos resultados da eleição essas foram de 3,0\% e 7,4\%, também respectivamente. Tal variação está relacionada, em nossa concepção, ao fato da pesquisa ter sido pós-

\footnotetext{
${ }^{15}$ Tomando como base a questão Eu vou falar o nome de várias instituições e gostaria que o (a) senhor (a) dissesse se avalia a situação de cada uma como ótima, boa, ruim ou péssima, a elaboração do índice considerou a avaliação das seguintes: governo federal, partidos políticos, congresso.

${ }^{16}$ Elaborado a partir das respostas às perguntas: Algumas pessoas dizem que faz uma grande diferença quem governa o Brasil. Outras dizem que não faz diferença quem governa o Brasil. Gostaria que o (a) senhor (a) desse uma nota de 1 a 5 . 05 significa que faz uma grande diferença quem governa, e o 1 que não faz nenhuma diferença quem governa o Brasil. O que o (a) senhor (a) acha?; Algumas pessoas dizem que o nosso voto influencia muito no que acontece no Brasil, outras dizem que o nosso voto não influencia nada do que acontece no Brasil. Gostaria que o (a) senhor (a) desse uma nota de 1 a 5 . 0 5 significa que o nosso voto influencia muito, e 1 significa que o nosso voto não influencia nada no que acontece no Brasil. O que o senhor acha?

${ }^{17}$ Elaborado a partir das respostas às questões: De uma maneira geral, o (a) senhor (a) está satisfeito (a), pouco satisfeito (a) ou não está satisfeito (a) com o funcionamento da democracia no Brasil; e A democracia tem alguns problemas, mas e melhor do que qualquer outra forma de governo. O (a) sr (a) concorda ou discorda dessa afirmação? Muito ou pouco?

${ }^{18}$ Elaborado a partir das questões: $O$ (a) senhor (a) lê jornal?; [...] assistiu telejornais com notícias nacionais essa semana?; [...] ouviu rádio esta semana?

${ }^{19}$ Elaborado a partir das questões: Um candidato oferece uma cadeira de rodas para um deficiente físico, o que ele deveria fazer?; [...] oferece uma cesta básica [...]; um candidato consegue uma vaga para o filho de dela [...]; [...] um candidato oferece para uma mãe que tem um filho doente dinheiro para o tratamento médico, o que ela deveria fazer [...]; [...] oferece um caminhão de tijolos para várias famílias que precisam acabar de construir suas casas [...]; oferece reformar um campo de futebol para um grupo de amigos que jogam bola juntos toda semana [...].
} 
eleitoral, o que coloca a possibilidade de racionalização do eleitor com relação ao destino do seu voto. Feita essa ressalva, passemos aos dados da pesquisa.

Tabela 1 - As bases sócio-econômicas da alienação eleitoral em \%

\begin{tabular}{|c|c|c|c|c|}
\hline \multirow[b]{2}{*}{ Idade } & \multicolumn{2}{|c|}{$\begin{array}{c}\text { Não Abstenções } \\
\text { (NA)/Abstenções (A) }\end{array}$} & \multicolumn{2}{|c|}{$\begin{array}{c}\text { Votos Válidos (VV) } \\
\text { Brancos e Nulos } \\
\text { (BN) }\end{array}$} \\
\hline & NA & A & VV & BN \\
\hline 16 a 24 & 93,1 & 6,9 & 97,9 & 2,1 \\
\hline 25 a 34 & 86,2 & 13,8 & 96,4 & 3,6 \\
\hline 35 a 44 & 91,8 & 8,2 & 97,3 & 2,7 \\
\hline 45 a 59 & 93,8 & 6,2 & 96,0 & 4,0 \\
\hline 60 ou mais & 77,2 & 22,8 & 98,4 & 1,6 \\
\hline Total & 89,2 & 10,8 & 97,1 & 2,9 \\
\hline Qui-quadrado & 78,568 & 0,000 & 4,960, & 0,291 \\
\hline \multicolumn{5}{|l|}{ Sexo } \\
\hline Masculino & 89,7 & 10,3 & 96,9 & 3,1 \\
\hline Feminino & 88,7 & 11,3 & 97,1 & 2,9 \\
\hline Total & 89,2 & 10,8 & 97,0 & 3,0 \\
\hline Qui-quadrado & 0,658 & 0,417 & 0,118, & 0,731 \\
\hline \multicolumn{5}{|l|}{ Escolaridade } \\
\hline Até 8a. série & 87,1 & 12,9 & 96,9 & 3,1 \\
\hline 2o. grau & 89,1 & 10,9 & 96,5 & 3,5 \\
\hline Superior ou mais & 98,1 & 1,9 & 99,0 & 1,0 \\
\hline Total & 89,2 & 10,8 & 97,1 & 2,9 \\
\hline Qui-quadrado & 32,794 & 0,000 & 4,830 & 0,89 \\
\hline \multicolumn{5}{|l|}{ Pop. Econ. Ativa } \\
\hline Pea & 91,2 & 8,8 & 96,9 & 3,1 \\
\hline Não-Pea & 84,5 & 15,5 & 97,5 & 2,5 \\
\hline Total & 89,2 & 10,8 & 97,1 & 2,9 \\
\hline Qui-quadrado & 24,188 & 0,188 & 0,470, & 0,493 \\
\hline \multicolumn{5}{|l|}{ Renda Familiar } \\
\hline Até 1 SM & 86,1 & 13,9 & 97,1 & 2,9 \\
\hline+ de 1 até 3 SM & 88,6 & 11,4 & 97,3 & 2,7 \\
\hline + de 3 até 5 SM & 87,2 & 12,8 & 95,4 & 4,6 \\
\hline+ de 5 até 10 SM & 94,3 & 5,7 & 97,6 & 2,4 \\
\hline+ de $10 \mathrm{SM}$ & 93,5 & 6,5 & 97,9 & 2,1 \\
\hline Total & 89,2 & 10,8 & 97,1 & 2,9 \\
\hline Qui-quadrado & 24,289 & 0,000 & 4,214, & 0,378 \\
\hline
\end{tabular}

Os dados acima apresentam associações significativas, principalmente entre as abstenções, e as variáveis relacionadas à idade, renda e escolaridade. Nesse sentido, pode-se afirmar que, quanto maior 
a renda e escolaridade, menores foram as probabilidades de um eleitor se abster e, em menor grau, votar nulo ou branco em 2002, nas eleições presidenciais. Também a idade apresenta uma associação significativa, principalmente os jovens (13,8\% daqueles entre 25 e 34 anos não compareceram) e os acima de 60 anos (22,8\%). Nesse último caso, a variação pode ser explicada pela não obrigatoriedade do voto para aqueles com idade superior a 70 anos. Em termos de gênero, as diferenças são pouco significativas, a não ser para a abstenção, com predomínio dos homens.

Os dados apresentados acima são corroborados pelo estudo de Costa (2007), relativo à alienação eleitoral nas eleições presidenciais de 2002. O autor chegou às seguintes conclusões, com relação ao valor explicativo das variáveis sócio-econômicas e demográficas:

1. No modelo construído pelo autor, o IDH do município foi a variável que melhor explica as taxas de votos nulos e em menor grau, a extensão territorial (p. 245) ${ }^{20}$;

2. Os votos brancos seriam explicados, também, em grande parte pelo IDH, seguido da região e densidade eleitoral. $54 \%$ da variação nos votos brancos são explicadas por essas variáveis;

3. Já a abstenção eleitoral tem como principais determinantes, segundo Costa (2007, p. 246), o Índice de Exclusão Social e a extensão territorial.

As constatações de Costa (2007) apontam para o peso relativo das variáveis sócio-econômicas na compreensão do fenômeno da alienação no país. Porém, como visto acima, percentual significativo da variação nesses dados não se deve a tais variáveis. Nesse sentido, nossa indagação vai no sentido da identificação de elementos atitudinais que poderiam ajudar a compreender o fenômeno da alienação.

A Tabela 2, abaixo, apresenta os resultados do cruzamento de alguns índices relacionados às atitudes dos cidadãos e 0 seu comportamento político (em termos de comparecimento, abstenção,

${ }^{20} 64 \%$ da variação dos votos nulos são explicados pelo modelo (Costa, 2007, p. 245). 
voto branco ou nulo).

Tabela 2 - Atitudes políticas e alienação eleitoral em \%

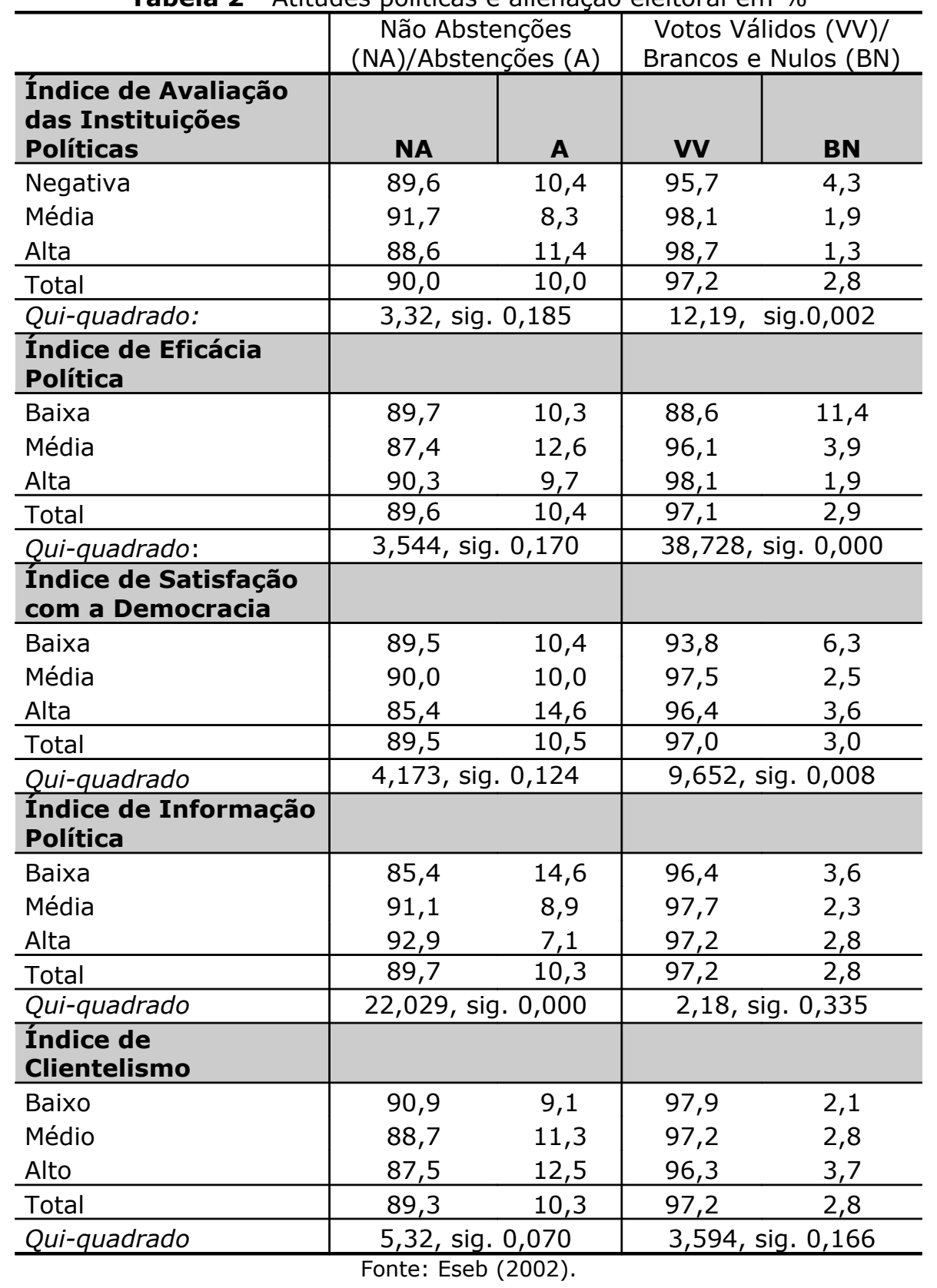

Uma primeira constatação com relação à tabela acima é que a abstenção é pouco relacionada a todos os índices que foram criados. Em outras palavras, os dados indicam que a decisão de comparecer e/ou se abster é pouco relacionada à forma como o cidadão percebe a política e 
suas instituições (nenhuma associação significativa). Nesse sentido, com relação à abstenção, como já destacado em trabalhos como os de Lima Júnior (1993), Reis (1991) e Costa (2007), a dimensão sóciodemográfica parece desempenhar um peso mais significativo, em termos da definição dos custos e oportunidades para a participação política. Questões relacionadas à exclusão social, distância do local de votação e ao o deslocamento (e seus custos) são explicativas do porquê em regiões mais pobres, mais extensas e com menor densidade demográfica as taxas de abstenção são relativamente maiores que em contextos de maior urbanização e menor exclusão social (COSTA, 2007).

Por sua vez, quando passamos a analisar os votos brancos e nulos, verifica-se que o comportamento das variáveis obedece a outra lógica. Com relação ao primeiro índice (avaliação das instituições políticas), percebe-se uma diferença de mais de $3 \%$ entre aqueles que avaliam o funcionamento das instituições poliárquicas como péssimo e aqueles que fazem uma avaliação positiva de seu funcionamento. O teste de associação apresenta uma intensidade moderada entre as variáveis (gama 0,42, sig. 0,001).

Da mesma forma, os indivíduos que nutrem um alto sentimento de eficácia política subjetiva também são menos propensos a anular ou votar em branco. Quando observamos os extremos, identificamos uma variação maior que $9 \%$ em termos de opção entre votar num candidato ou o voto branco/nulo. O teste de associação entre as variáveis, mais uma vez apresentou um indicador moderado (gama 0,513, sig. 0,000).

Quanto ao nível de satisfação com a democracia, temos variações menores, porém obedecendo ao mesmo padrão das respostas anteriores, ou seja, quanto mais satisfeito, menor a alienação. Incluímos também um índice de informação política, no sentido de verificar se cidadãos mais bem informados sobre a política (através da exposição aos meios de comunicação), possuem maior propensão a participar. A associação foi pequena, mas também no sentido esperado (gama 0,231, sig. 0,144).

Por fim, criamos um índice de clientelismo. Aqui, pretendia-se verificar em que medida a aceitação de práticas clientelistas se relaciona 
ou não ao comportamento alienado. Os dados, apesar de mostrarem pequena associação, apontam para uma relação negativa entre clientelismo e votos válidos, ou seja, quanto mais o indivíduo aceita o clientelismo, menores são as possibilidades de ele escolher entre as ofertas do mercado político. Aceitar o clientelismo, nesse sentido, parece estar relacionado à valorização, por parte da cidadania, de formas extrainstitucionais de resolução de problemas políticos (gama -0,226, sig. 0,064).

\section{Considerações Finais}

No decorrer deste trabalho, buscamos analisar o fenômeno da alienação eleitoral no Brasil, tomando como parâmetro empírico as eleições presidenciais de 2002 (I turno). Os resultados da eleição apontam para a importância do fenômeno para a dinâmica de funcionamento da democracia brasileira, onde a expressão da alienação eleitoral foi superior aos os votos conquistados pelo segundo colocado (José Serra).

Num diálogo com a literatura, identificamos que predominam, no Brasil, explicações racionalistas e/ou sociológicas para o fenômeno. Em outras palavras, a alienação é explicada ou como produto de um cálculo de ganhos e perdas feitos pelo eleitor (entre comparecer ou não comparecer ou comparecer e se abster da escolha), ou em função do contexto sócio-econômico/demográfico em que este está inserido (classe social, renda, escolaridade, região, etc.).

Identificamos também que alguns autores percebem no fenômeno da alienação sinais de uma crise de legitimidade das instituições e/ou de desagregação social, onde o pressuposto comportamental é menos aquele do cálculo estratégico do eleitor e mais o de uma complexa cadeia de relações entre contexto, atitudes, valores e crenças, por um lado, e o comportamento, por outro. Foi nesse sentido que buscamos incluir variáveis típicas das pesquisas de cultura política em nossa análise.

Os dados, apesar da limitação dos instrumentos e testes utilizados, apontam para a importância da dimensão da cultura política 
na compreensão dos significados do fenômeno da alienação, principalmente se considerarmos sua expressão nos votos brancos e nulos. Reconhece-se, porém, que uma melhor interpretação do fenômeno, exigiria ampliar bases de dados e técnicas de análise, o que se pretende desenvolver em futuros trabalhos.

Julian Borba é mestre em Sociologia Política pela Universidade Federal de Santa Catarina, doutor em Ciência Política pela Universidade Federal o Rio Grande do Sul, professor na Universidade Federal de Santa Catarina.

Email: julian@cfh.ufsc.br

\section{Referências:}

ALMOND, Gabriel. The intellectual history of civic culture concept. In: ALMOND, Gabriel; VERBA, Sidney (Eds.). The civic culture revisited. London: Sage, 1989. p. 1-36.

- La teoría de la elección racional y las ciencias sociales. In: - Una disciplina segmentada: escuelas e corrientes en las $\overline{\text { ciencias }}$ politicas. México: Fondo de Cultura Económica. 1999. p. 170195.

ALMOND, Gabriel; VERBA, Sidney. The civic culture: political attitudes and democracy in five nations. Princeton: Princeton University Press, 1963.

(Eds.). The civic culture revisited. London: Sage, 1989.

BAQUERO, Marcello. Partidos e cultura política na América Latina: uma combinação de instabilidade política. In: (Org.). Desafios da democratização na América Latina. Porto Alegre: Ed. UFRGS/ La Salle, 1999. p. 15-30.

. Democracia, cultura e comportamento político: uma análise da situação brasileira. In: PERISSINOTTO, Renato; FUKS, Mario. Democracia: teoria e prática. Rio de Janeiro: Relumé Dumará. 2002. p. 105-140.

BAQUERO, Marcello; PRÁ, Jussara Reis. Democracia brasileira e cultura política no Rio Grande do Sul. Porto Alegre: Ed. UFRGS. 2007.

BARRY, Brian. Los sociólogos, los economistas y la democracia. Buenos Aires: Amorrortu Editores, 1970. 
CASTRO, Henrique Carlos de Oliveira de. Democracia e mudanças econômicas no Brasil, Argentina e Chile: um estudo comparativo de cultura política. 2000. 200 f. Tese (Doutorado em Ciência Política) Universidade Federal do Rio Grande do Sul, [2000].

CASTRO, Mônica Mata Machado de. Determinantes do comportamento eleitoral: a centralidade da sofisticação política. 1994. 239 f. Tese (Doutorado em Ciência Política), Instituto Universitário de Pesquisas do Rio de Janeiro, [1994].

CONVERSE, Philip E. The nature of belief systems in mass publics. In: APTER, David E. (Ed.) Ideology and discontent. New York: The Free Press, 1964. p. 206-261.

COSTA, Homero de Oliveira. Democracia e representação política no Brasil: uma análise das eleições presidenciais (1989-2002). Porto Alegre/Natal: Sulina/Ed. UFRN, 2007.

DOWNS, Anthony. Uma teoria econômica da democracia. São Paulo: Editora da Universidade de São Paulo, 1998.

ECKSTEIN, Harry. A culturalist theory of political change. American Political Science Review, Washington, v. 82, n. 3, p. 789-804, sep. 1988.

ELSTER, Jon. Peças e engrenagens das ciências sociais. Rio de Janeiro: Relumé-Dumará, 1994.

INGLEHART, Ronald. The renaissance of political culture. American Political Science Review, Washington, v. 82, n. 4, p. 1203-29, dec. 1998.

. Cultura e democracia. In: HARRISOM, Lawrence E.; HUNTINGTON, Samuel (Orgs.). A cultura importa: os valores que definem o progresso humano. Rio de Janeiro: Record, 2002. p. 133-154.

LIMA JÚNIOR, Olavo Brasil de. Democracia e instituições políticas no Brasil dos anos 80. São Paulo: Loyola, 1993.

LIPSET, Seymour Martin. O Homem político. Rio de Janeiro: Zahar, 1967.

NEUMAN, W. Russel. The paradox of mass politics: knowledge and opinion in the American electorate. Cambridge: Harvard University Press, 1986.

NICOLAU, Jairo. A participação eleitoral no Brasil. In: VIANA, Luiz Werneck. A democracia e os três poderes no Brasil. Belo Horizonte/Rio de Janeiro: Ed. UFMG/Iuperj/UCAM, FAPERJ, 2002. p. 255-296. 
- Dados eleitorais do Brasil. Disponível em <http://jaironicolau.iuperj.br>. Acesso em: 01 jul. 2008.

NORRIS, Pipa. Democratic phoenix: reinventing political activism. New York: Cambridge University Press, 2002.

PRZEWORSKI, Adam. Marxismo e escolha racional. Revista Brasileira de Ciências Sociais, São Paulo, v. 6, n. 3, p. 2-25, fev. 1988.

PUTNAM, Robert. Comunidade e democracia: a experiência da Itália moderna. Rio de Janeiro: FGV, 1996.

. Bowling alone: the collapse and revival of american community. New York: Simon and Schuster, 2000.

REIS, Antônio C. Alkmin. A participação eleitoral e seus correlatos sócioeconômicos. In: LIMA JÚNIOR, Olavo Brasil de. Sistema eleitoral: teoria e prática. Rio de Janeiro: Rio Fundo/IUPERJ, 1991.

REIS, Fábio Wanderley (Org.). Os partidos e o regime: a lógica do processo eleitoral brasileiro. São Paulo: Símbolo, 1978.

Política e racionalidade: Problemas de teoria e método de uma sociologia crítica da política. Belo Horizonte: Ed. UFMG, 2000.

. Sociologia política, ciência política e escolha racional. Revista Política \& Sociedade, Florianópolis, v. 1, n. 1, p. 37-55, set. 2002.

SANTOS, Wanderley Guilherme dos. Crise e castigo: partidos e generais na política brasileira. Rio de Janeiro: Vértice/IUPERJ, 1987.

SOARES, Glaucio Ary Dillon. Sociedade e política no Brasil: Desenvolvimento, Classe e Política durante a Segunda República. São Paulo: Difusão Européia do Livro, 1973.

STAMATTO, Maria Inês. Legitimidade do sistema partidário. O voto nulo e o voto em branco. In: BAQUERO, Marcello. Abertura política e comportamento eleitoral nas eleições de 1982 no Rio Grande do Sul. Porto Alegre: Ed. UFRGS, 1984. p. 86-102.

TRINDADE, Hélgio; CEW, Judson de. Confrontação política e decisão eleitoral: as eleições municipais de 1976 em Caxias do Sul. In: REIS, Fábio Wanderley. Os partidos e o regime: a lógica do processo eleitoral brasileiro. São Paulo: Símbolo, 1978. p. 145-211.

VITULLO, Gabriel. Participción electoral, comportamiento político e desestruración social en Argentina e Brasil. In: LEVY, Bettina (Org.). Crisis y conflictos en capitalismo latino-americano: Lecturas politicas. Buenos Aires: Clacso, 2002. p. 223-247. 
Teorias da democratização e democracia na Argentina. Porto Alegre/Natal: Sulina/Ed. UFRN, 2007.

\section{Anexo}

Tabela 1 - Presidente da República. Comparecimento, Abstenção, Votos em Branco, Votos Nulos e Votos nos Candidatos (\%) - 1989-2006

\begin{tabular}{c|c|c|c|c|c}
\multicolumn{6}{c}{ Branco, Votos Nulos e Votos nos Candidatos (\%) - 1989-2006 } \\
\hline & $\begin{array}{c}\text { COMP } \\
.\end{array}$ & ABST. & BRANCO & NULOS & CANDIDATOS \\
\hline BRASIL (1989 I Turno) & 88,1 & 11,9 & 1,6 & 4,8 & 93,5 \\
\hline BRASIL (1989 II Turno) & 85,6 & 14,4 & 1,4 & 4,4 & 94,2 \\
\hline BRASIL (1994) & 82,2 & 17,8 & 9,2 & 9,6 & 81,2 \\
\hline BRASIL (1998) & 78,5 & 21,5 & 8,0 & 10,7 & 81,3 \\
\hline BRASIL (2002 - I turno) & 82,3 & 17,7 & 3,0 & 7,4 & 89,6 \\
\hline BRASIL (2002 II Turno) & 79,5 & 20,5 & 1,9 & 4,1 & 94,0 \\
\hline BRASIL (2006 - I Turno) & 83,3 & 16,7 & 2,7 & 5,7 & 91,6 \\
\hline BRASIL (2006 - II Turno) & 81,0 & 19,0 & 1,3 & 4,7 & 94,0 \\
\hline \multicolumn{6}{c}{ Fonte: Nicolau, Jairo. Dados eleitorais do Brasil. Disponível em: } \\
< http://jaironicolau.iuperj.br>. Acesso em: 01 jul. 2008.
\end{tabular}

Tabela 2 - Governador. Comparecimento, Abstenção, Votos em Branco, Votos Nulos e Votos nos Candidatos (\%) - 1989-2006

\begin{tabular}{c|c|c|c|c|c}
\multicolumn{6}{c}{ Votos Nulos e Votos nos Candidatos (\%) - 1989-2006 } \\
\hline & $\begin{array}{c}\text { COMP } \\
\text {. }\end{array}$ & ABST. & BRANCO & NULOS & CANDIDATOS \\
\hline BRASIL (1990) & 85,8 & 14,2 & 24,2 & 75,8 & 85,8 \\
\hline BRASIL (1994 - I Turno) & 82,2 & 17,8 & 17,9 & 8,0 & 74,2 \\
\hline $\begin{array}{c}\text { BRASIL (1994 - II } \\
\text { Turno) }\end{array}$ & 78,2 & 21,8 & 1,1 & 9,7 & 89,2 \\
\hline BRASIL (1998 - I Turno) & 78,5 & 21,5 & 12,1 & 8,7 & 79,3 \\
\hline $\begin{array}{c}\text { BRASIL (1998 - II } \\
\text { Turno) }\end{array}$ & 78,4 & 21,6 & 1,5 & 4,4 & 94,1 \\
\hline BRASIL (2002 - I turno) & 82,3 & 17,7 & 4,0 & 7,3 & 88,7 \\
\hline BRASIL (2002 II Turno) & 82,1 & 17,9 & 1,6 & 4,2 & 94,2 \\
\hline BRASIL (2006 - I Turno) & 83,3 & 16,7 & 4,1 & 6,8 & 89,0 \\
\hline BRASIL (2006 - II & 81,5 & 18,5 & 1,8 & 8,4 & 89,8 \\
\hline Turno) &
\end{tabular}

Fonte: Nicolau, Jairo. Dados eleitorais do Brasil. Disponível em: <http://jaironicolau.iuperj.br>. Acesso em: 01 jul. 2008. 
Tabela 3 - Câmara dos Deputados. Comparecimento, Abstenção, Votos em Branco, Votos Nulos e Votos nos Partidos e Candidatos(\%) - 19902006

\begin{tabular}{c|c|c|c|c|c}
\hline & COMP. & ABST. & BRANCO & NULOS & CANDIDATOS \\
\hline 1990 & 85,8 & 14,2 & 30,0 & 13,7 & 56,3 \\
\hline 1994 & 82,2 & 17,8 & 16,5 & 25,2 & 58,3 \\
\hline 1998 & 78,5 & 21,5 & 10,2 & 9,8 & 80,0 \\
\hline 2002 & 82,3 & 17,7 & 4,7 & 2,9 & 92,4 \\
\hline 2006 & 83,3 & 16,7 & 6,3 & 4,8 & 88,9 \\
\hline
\end{tabular}

Tabela 4 - Prefeito Comparecimento, Abstenção, Votos em Branco, Votos Nulos e Votos nos Partidos e Candidatos (\%) - 1990 - 2006

\begin{tabular}{c|c|c|c|c|c}
\hline & COMPARECIMENTO & ABST. & BRANCO & NULOS & CANDIDATOS \\
\hline 1996 & 81,7 & 18,3 & 2,3 & 6,0 & 91,7 \\
\hline 2000 & 85,0 & 15,0 & 2,5 & 5,9 & 91,6 \\
\hline 2000 & 83,7 & 16,3 & 2,5 & 3,9 & 93,6 \\
\hline 22004 & 85,8 & 14,2 & 1,9 & 5,5 & 92,6 \\
\hline 22004 & 81,9 & 17,1 & 1,5 & 3,9 & 94,6 \\
\hline
\end{tabular}

Fonte: Nicolau, Jairo. Dados eleitorais do Brasil. Disponível em:

<http://jaironicolau.iuperj.br>. Acesso em: 01 jul. 2008.

Tabela 5 - Comparação entre os resultados eleitorais e resultados do ESEB

\begin{tabular}{l|l|l|l|l|l}
\hline & COMP. & ABST. & BRANCOS & NULOS & CANDIDATOS \\
\hline $\begin{array}{l}\text { BRASIL } \\
(2002-\text { I } \\
\text { turno })\end{array}$ & $\begin{array}{l}94.804 .126 \\
(82,3 \%)\end{array}$ & $\begin{array}{l}20.449 .690 \\
(17,7 \%)\end{array}$ & $\begin{array}{l}3.873 .720 \\
(3,0 \%)\end{array}$ & $\begin{array}{l}6.976 .10 \\
(7,4 \%)\end{array}$ & $\begin{array}{l}84.951 .144 \\
(89,6 \%)\end{array}$ \\
\hline $\begin{array}{l}\text { ESEB } \\
(2002)\end{array}$ & & $10,8 \%$ & $1,0 \%$ & $1,7 \%$ & \\
\hline
\end{tabular}

Fonte: Nicolau, Jairo. Dados eleitorais do Brasil. Disponível em: <http://jaironicolau.iuperj.br>. Acesso em: 01 jul. 2008. 